\title{
Cellular angiofibroma in women: a review of the literature
}

\author{
Vincenzo Dario Mandato ${ }^{1}$, Susanna Santagni ${ }^{1 *}$, Alberto Cavazza ${ }^{2}$, Lorenzo Aguzzoli ${ }^{1}$, Martino Abrate ${ }^{1}$ \\ and Giovanni Battista La Sala ${ }^{1,3}$
}

\begin{abstract}
Cellular Angiofibroma (CA) represents a quite recently described mesenchymal tumour that occurs in both genders, in particular in the vulvo-vaginal region in women and in the inguino-scrotal area in men. The first description of this tumour dates from Nucci et al. article in 1997; since then, the literature reports different reviews and case report of this tumour in both genders, but no article specifically addressing CA treatment and follow-up in women. In this review we collected all 79 published female CA cases, analyzing the clinical, pathological and immunohistochemical features of the tumour.

CA affects women mostly during the fifth decade of life, it is generally a small and asymptomatic mass that mainly arises in the vulvo-vaginal region, although there are reported pelvic and extra-pelvic cases. The treatment requires a simple local excision due to an extremely low ability to recurrent locally and no chance to metastasize. Throughout the immunohistochemical and pathological findings it is also easily possible a differential diagnosis from the other soft tissue tumours which affect the vulvo-vaginal area, such as spindle cell lipoma, solitary fibrous tumour, angiomyofibroblastoma and aggressive angiomyxoma.
\end{abstract}

Keywords: Cellular angiofibroma, Vulvovaginal soft tissue tumour, Mesenchymal tumour, Vulvovaginal benign tumour

\section{Introduction}

Cellular angiofibroma (CA) belongs to soft tissue tumours that predominantly occur in the distal genital tract of both genders: vulvo-vaginal region in women and inguino-scrotal area in men [1, 2], although extragenital localizations have also been described [3-5].

The first soft tissue tumour with a relatively pelvic site-specificity was a benign stromal polyp described in the early 1960 [6].

Among the mesenchymal tumours involving the vulva, we can distinguish the lesions that can arise at any site, including the vulva, and those more characteristics of this area. The former group includes leiomyoma (Fig. 1), lipoma (Fig. 2) and solitary fibrous tumour (Fig. 3) while the second group includes CA (Fig. 4) along with aggressive angiomyxoma (Fig. 5), angiomyofibroblastoma (Fig. 6) and fibroepithelial stromal polyp [7].

\footnotetext{
* Correspondence: susanna.santagni@asmn.re.it

${ }^{1}$ Unit of Obstetrics and Gynecology, IRCCS-Arcispedale S. Maria Nuova di Reggio Emilia, Viale Risorgimento n 80, Reggio Emilia, Italy

Full list of author information is available at the end of the article
}

Cellular angiofibroma is a rare benign mesenchymal lesion, first described by Nucci et al. in 1997 [1] in a series of 6 cases that occurred almost exclusively in the vulva of middle-aged women. A short time later, Laskin et al. [2] described 11 cases of a histologically similar lesion named "angiomyofibroblastoma-like" tumour, which affects the adult men in the inguino-scrotal area. The World Health Organization classification [8] established that the term "Cellular angiofibroma" includes this kind of lesion in both females and males, because there are no reproducible morphologic differences between the two genders. Macroscopically these lesions are commonly well circumscribed, localized in the superficial soft tissue and are characterized by 2 main components: bland spindle cells and small to medium-sized vessels with mural hyalinization [9].

Since the first description by Nucci, only few studies have been published in the literature, most of which consisted of single case-reports or reviews which include cases from both genders.
Ciomed Central

(C) 2015 Mandato et al. This is an Open Access article distributed under the terms of the Creative Commons Attribution License (http://creativecommons.org/licenses/by/4.0), which permits unrestricted use, distribution, and reproduction in any medium, provided the original work is properly credited. The Creative Commons Public Domain Dedication waiver (http:// creativecommons.org/publicdomain/zero/1.0/) applies to the data made available in this article, unless otherwise stated. 


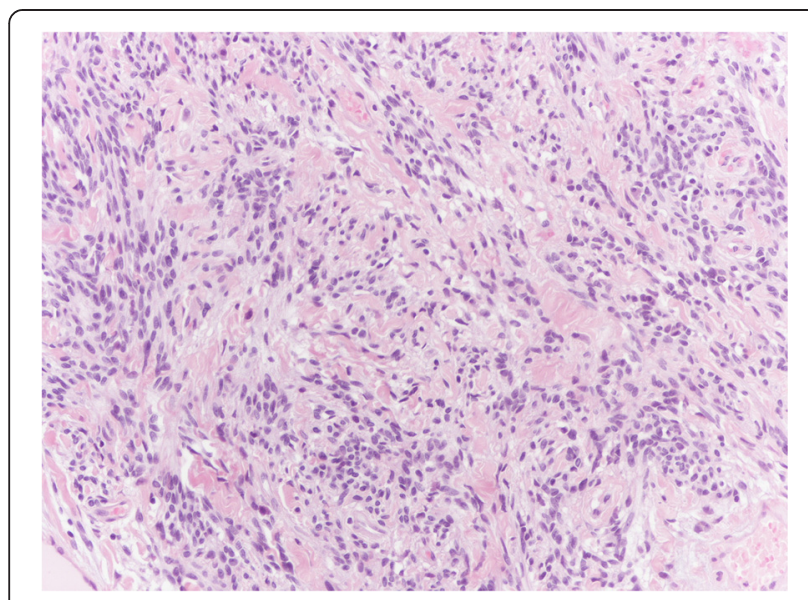

Fig. 1 Leiomyoma at hematoxylin-eosin, 200X

Here, we reviewed all the cases of CA arising in women since 1997, to clarify the outcome and to identify the best treatment.

\section{Review}

\section{Materials and methods}

We collected and analyzed the published articles in the literature regarding CA from January 1997 to December 2014, using Pubmed research and the terminologies "cellular angiofibroma", "vulvovaginal mesenchymal tumour", "vulvovaginal benign tumour", "vulvovaginal stromal tumour" and "vulvovaginal soft tissue tumour". We selected only the cases involving the female gender: a total of 79 published cases of CA were found. Where possible, we contacted the authors to update the follow-up data, in particular regarding local recurrences and/or metastases.

In the Tables 1 and 2 are reported the main clinical features of the 74 vulvo-vaginal and pelvic $\mathrm{CA}$ and the clinical finding of the 6 extra-pelvic CA, respectively.

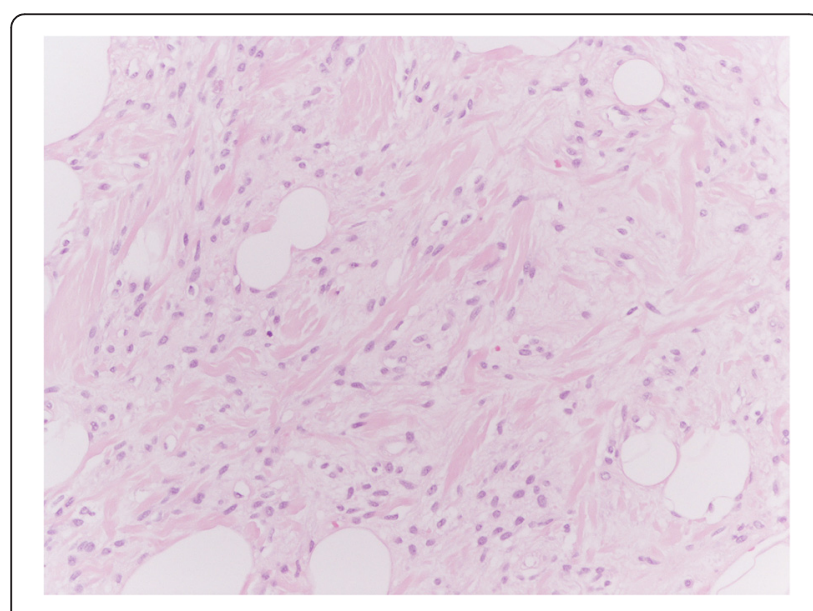

Fig. 2 Lipoma at hematoxylin-eosin, 200X

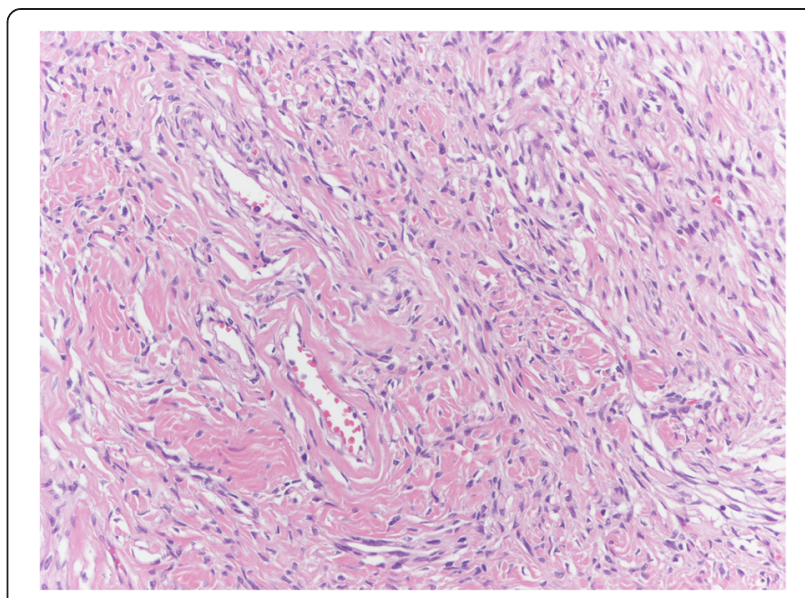

Fig. 3 Solitary fibrous at hematoxylin-eosin, 200X

\section{Results}

\section{Clinical features}

The 79 affected women have an age at presentation ranging from 20 to 77 years (mean 46.1 years). The most common anatomic site is the vulvo-vaginal region, in particular labium majus area and vulva overall (18 and 35 cases, respectively). Outside the vulvo-vaginal region, 5 pelvic localizations are reported, including 4 perineum and an urethral site. Six extra-pelvic CA are reported, such as a left hip, lateral knee, chest wall, left axilla and breasts [10], left hypocondrium [3,5] and more recently, we have reported the first case of retroperitoneal CA arising in right paravesical space of a post-menopausal woman [11].

The tumour size ranges from 0.6 to $12.3 \mathrm{~cm}$, with a mean size of $3.6 \mathrm{~cm}$. A clinical diagnosis before surgery is reported only in 25 cases. Among these, the most common clinical presentation resembles a Bartholin's cyst $(12 / 25,48 \%$ of cases), a not-specific solid mass (7/25, $28 \%$ of cases), vulval cyst $(3 / 25,12 \%$ of cases),

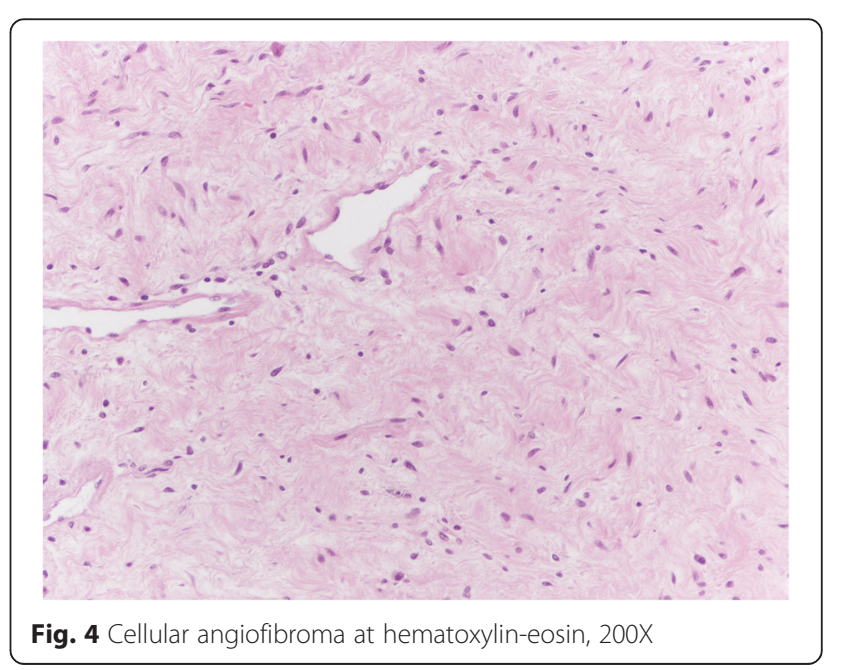




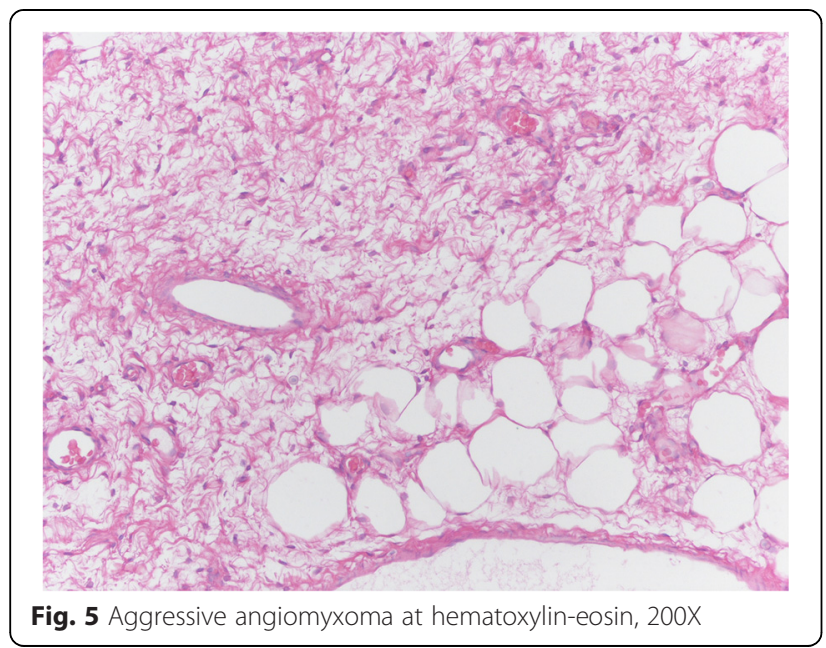

leyomioma (2/12, $8 \%$ of cases) and lipoma $(1 / 25,4 \%$ of cases). In 8 cases of CA the time occurred between the tumour's occurrence and the surgical treatment is reported: the mean is 16.6 month, ranging from 2 to 36 months.

CA is usually treated by simple excision; the involvement or not of the surgical margins is reported in $47 / 78$ (60.2\%) CA with 18 positive surgical margins (18/47, $38.2 \%)$ and 29 negative surgical margins (29/47, $61.7 \%$ ); only 5 cases $(5 / 18,27.8 \%)$ of re-excision because involved the surgical margin are reported.

Follow-up data are reported in 48/79 (60.7\%) cases with a range of 3-240 months (mean 46.6 months): the available follow-up data show that CA tends to not develop local recurrences or metastasis also in case of atypia or sarcomatous transformation. In 7 of the 12 patients with atypia or sarcomatous transformation follow up data were available, no recurrence or metastases were reported after a median follow-up of 14 months [9].

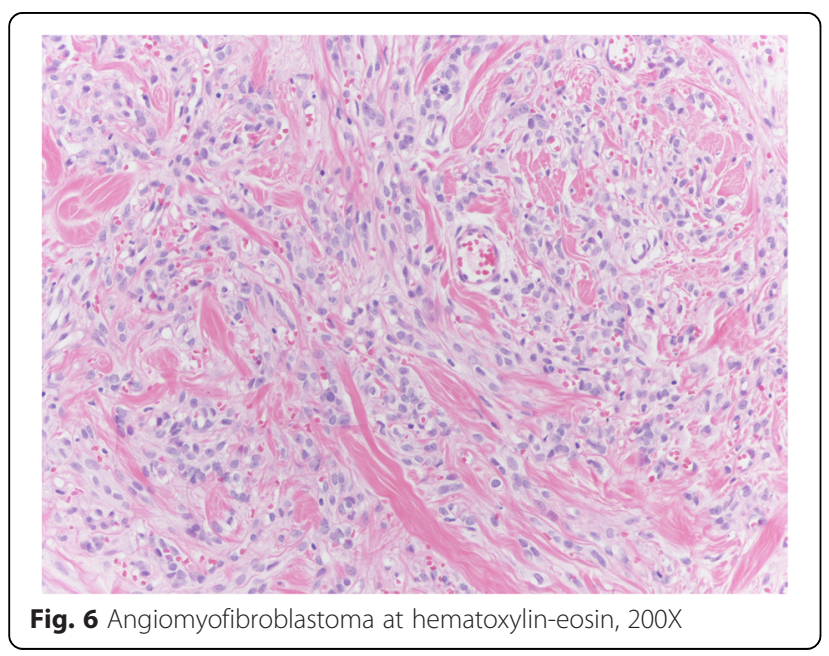

One patients died of metastatic carcinoma of unknown primary origin, after 27 months from the diagnosis of CA with sarcomatous component. In an another one, the women died of breast cancer, 59 months after the $\mathrm{CA}$ diagnosis, without $\mathrm{CA}$ recurrence or metastases found meanwhile.

Only a local recurrence of vulvar CA is described after 6 months follow-up [12]. CA has been initially excised with a rim of free-tumour tissue [12].

\section{Pathological features}

A macroscopic/microscopic description was reported in $63 / 79$ (79.7 \%) CA. Grossly, the neoplasm is described as white or yellowish nodules, mostly firm and partly gelatinous of cystic in appearance, with a cut surface white tan to grayish in color. Macroscopically, three cases is recorded as polypoid lesions [13] and in other few cases is appreciated a multilobulated appearance. CA is usually well-circumscribed, although focal extension into surrounding soft tissue can be seen. Most lesions were found in superficial soft tissue while 5 cases, all in the vulvovaginal region, involve dermis [3]. There is reported only one case with foci of haemorrhage [3] and none showing foci of necrosis.

Microscopically, the CA is a cellular neoplasm, composed of bland spindle shaped cells, proliferating in an edematous to fibrous stroma, containing wispy collagen bundles, numerous small to medium-sized thick-walled, often hyalinized, vessels and a minor component of adipose tissue [7]. The spindle cell component in most cases is quite cellular and randomly distributed throughout the lesion, focally forming short fascicles but generally without any particular pattern [3]. The spindle cells usually have short, fusiform, ovoid, sometimes tapering or polygonal nuclei with incospicuous nucleoli, while their cytoplasm is palely eosinophilic with indistinct, illdefined borders or bipolar dendritic processes. Nuclear grooves and intranuclear inclusions are commonly observed [13]. A moderate number of inflammatory cells, comprising lymphocytes and rarely neutrophils, are scattered throughout the stroma [3]; the mast cells are often abundant while multinucleated giant cells or epithelioid cells are absent in this neoplasm.

Mitotic activity is very variable: indeed, a prominent mitotic activity may be occasionally observed, and abnormal mitoses and cellular atypia are rarely present.

CA with atypia or sarcomatous trasformation was reported in 12 women [9], no necrosis or hemorrhage was observed in any case and the atypical or sarcomatous component wasn't morphologically recognizable on macroscopically examination. Microscopically, the atypical changes ranged from severely atypical cells disseminated within a background of usual CA to the formation of a discrete atypical foci. Similarly, the sarcomatous 
Table 1 Clinical features of 74 cases of Cellular Angiofibroma in vulvo-vaginal and pelvic regions

\begin{tabular}{|c|c|c|c|c|c|c|c|}
\hline Case & Age & Author & Site & Size (media, cm) & Treatment & Follow-up (Months) & Recurrence \\
\hline 1 & 50 & Nucci & Vulva & 1,2 & Simple excision & UK & UK \\
\hline 2 & 46 & Nucci & Lab maj & 2 & Local excision +2 reexcisions & 19 & NER \\
\hline 3 & 39 & Nucci & Lab & 2,15 & Simple excision & 12 & NER \\
\hline 4 & 49 & Nucci & Lab & 1,2 & Simple excision & UK & UK \\
\hline 5 & 43 & Nucci & Vulva & 2,3 & UK & UK & UK \\
\hline 6 & 41 & Nucci & perineum & 3 & UK & UK & UK \\
\hline 7 & 37 & Colombat & Lab & 2,5 & UK & UK & UK \\
\hline 8 & 37 & Curry & Clitoral Hood & 3,5 & UK & 15 & UK \\
\hline 9 & 53 & Dufau & Lab maj & 3,3 & UK & UK & UK \\
\hline 10 & 46 & Dargent & Lab maj & 2,33 & Simple excision & 149 & NER \\
\hline 11 & 49 & Dargent & Clitoris & 2,66 & Simple excision & 161 & NER \\
\hline 12 & 49 & Iwasa & Lab maj & 2 & Simple excision & 5 & UK \\
\hline 13 & 39 & Iwasa & Vulva & / & UK & UK & UK \\
\hline 14 & 46 & Iwasa & Lab maj & 2 & Simple excision & 168 & NER \\
\hline 15 & 50 & Iwasa & Vulva & 1,5 & Simple excision & UK & UK \\
\hline 16 & 42 & Iwasa & Vulva & 3 & Simple excision & 75 & NER \\
\hline 17 & 42 & Iwasa & Perineum & / & UK & UK & UK \\
\hline 18 & 75 & Iwasa & Vulva & 2,8 & Simple excision & 59 & Died for Breast cancer \\
\hline 19 & 27 & Iwasa & Lab maj & 1,1 & Local excision + reexcision & 50 & NER \\
\hline 20 & 41 & Iwasa & Vulva & 2,7 & Simple excision & 54 & NER \\
\hline 21 & 68 & Iwasa & Vulva & / & Simple excision & 17 & NER \\
\hline 22 & 59 & Iwasa & Lab maj & 2 & Simple excision & 41 & NER \\
\hline 23 & 49 & Iwasa & Vulva & / & UK & UK & UK \\
\hline 24 & 37 & Iwasa & Hymen & 4,8 & Local excision with positive margins & 24 & NER \\
\hline 25 & 38 & Iwasa & vagina & / & UK & UK & UK \\
\hline 26 & 46 & Iwasa & Vulva & 2,9 & Simple excision & 35 & NER \\
\hline 27 & 47 & Iwasa & Lab maj & 1,4 & Simple excision & 44 & NER \\
\hline 28 & 22 & Iwasa & Inguinal region & 12 & Local excision + reexcision & 18 & NER \\
\hline 29 & 52 & Iwasa & Urethra & / & UK & UK & UK \\
\hline 30 & 47 & Iwasa & Vulva & / & UK & UK & UK \\
\hline 31 & 48 & Iwasa & Lab maj & 3 & Simple excision & 8 & NER \\
\hline 32 & 24 & Iwasa & Vagina & 11 & UK & 6 & NER \\
\hline 33 & 31 & Iwasa & Perineum & 4 & Simple excision & UK & UK \\
\hline 34 & 58 & Iwasa & Vagina & 0,6 & Simple excision & UK & UK \\
\hline 35 & 50 & Iwasa & Vulva & 1,8 & Simple excision & 6 & NER \\
\hline 36 & 58 & Iwasa & Vulva & 3 & Simple excision & 9 & NER \\
\hline 37 & 50 & Iwasa & Vulva & / & UK & UK & UK \\
\hline 38 & 49 & McCluccage & Lab maj & 4 & Simple excision & 6 & Local recurrence \\
\hline 39 & 20 & McCluccage & Not specified & 2,4 & Simple excision & 240 & NER \\
\hline 40 & 65 & McCluccage & Lab maj & 5 & Simple excision & 12 & NER \\
\hline 41 & 59 & McCluccage & Vulva & 2 & Simple excision & 18 & NER \\
\hline 42 & 58 & Chen & Vulva & 2,7 & Piecemeal excision & 75 & NER \\
\hline 43 & 52 & Chen & Vulva & 3 & Simple excision & 27 & $\begin{array}{l}\text { NER, died for } \\
\text { cancer of UK origin }\end{array}$ \\
\hline
\end{tabular}


Table 1 Clinical features of 74 cases of Cellular Angiofibroma in vulvo-vaginal and pelvic regions (Continued)

\begin{tabular}{|c|c|c|c|c|c|c|c|}
\hline 44 & 34 & Chen & Vulva & 1,2 & Simple excision & UK & UK \\
\hline 45 & 32 & Chen & Vulva & 4,85 & Simple excision & UK & UK \\
\hline 46 & 25 & Chen & Vulva & 1,3 & Simple excision & 42 & NER \\
\hline 47 & 43 & Chen & Vulva & 2,5 & Simple excision & 2 & NER \\
\hline 48 & 59 & Chen & Vulva & 1,3 & Simple excision & 14 & NER \\
\hline 49 & 46 & Chen & Vulva & 6,5 & Simple excision & 4 & NER \\
\hline 50 & 71 & Chen & Vulva & 7,5 & Simple excision & UK & UK \\
\hline 51 & 39 & Chen & Vulva & / & Simple excision & 7 & NER \\
\hline 52 & 46 & Chen & Vulva & 2 & Simple excision & UK & UK \\
\hline 53 & 41 & Flucke & Perineum & 3 & Simple excision & UK & UK \\
\hline 54 & 39 & Flucke & Vagina & 1 & Local excision with positive margins & 75 & NER \\
\hline 55 & 50 & Flucke & Vulva & 3 & Local excision + reexcision & 55 & NER \\
\hline 56 & 51 & Flucke & Lab maj & 2,7 & Marginal excision & 66 & NER \\
\hline 57 & 44 & Flucke & Lab maj & 2,3 & Simple excision & UK & UK \\
\hline 58 & 50 & Flucke & Vulva & 4 & Local excision with positive margins & UK & UK \\
\hline 59 & 48 & Flucke & Vulva & 8,5 & Simple excision & UK & UK \\
\hline 60 & 42 & Flucke & Vulva & 2,2 & Simple excision & UK & UK \\
\hline 61 & 63 & Flucke & Clitoris & 2,5 & Local excision with positive margins & 38 & NER \\
\hline 62 & 27 & Flucke & Lab maj & 8 & Marginal excision & UK & UK \\
\hline 63 & 42 & Flucke & Vulva & 1,7 & Simple excision & 30 & UK \\
\hline 64 & 46 & Flucke & Lab maj & 3 & Marginal excision & UK & UK \\
\hline 65 & 55 & Flucke & Vulva & 2,3 & Simple excision & 12 & NER \\
\hline 66 & 57 & Flucke & Vulva & 4,5 & Simple excision & 6 & NER \\
\hline 67 & 47 & Flucke & Vulva & 1,5 & Local excision with positive margins & UK & UK \\
\hline 68 & 39 & Flucke & Vagina & 9 & Marginal excision & UK & UK \\
\hline 69 & 51 & Rua Micheletti & Lab maj & 4,6 & Simple excision & 112 & NER \\
\hline 70 & 31 & Kerkuta & Lab maj & 4 & Simple excision & 10 & NER \\
\hline 71 & 77 & Lane & Lab & 4 & Simple excision & 12 & NER \\
\hline 72 & 26 & Arsenovic & Vulva & 8,5 & Simple excision & 90 & NER \\
\hline 73 & 55 & Maggiani & Vagina & 12,3 & UK & UK & UK \\
\hline 74 & 20 & Ahmadnia & Both lab maj & / & Simple excision & 12 & NER \\
\hline
\end{tabular}

NER not evidence of recurrence, UK unknown

component showed variable features, including an atypical lipomatous tumour-like component, pleomorphic liposarcoma and pleomorphic sarcoma [9].

\section{Immunohistochemical features}

In the Table 3 are summarized the available data about the immunohistochemical findings of the selected articles. Immunohistochemical findings were reported only in 44/79 (55.7\%) published CA because many articles don't distinguish the immunohistochemical features between the male and female tumours.

Tumour cells are consistently negative for S-100protein (40/40 cases, $100 \%$ ), while they show positivity for CD34 in $45.4 \%(20 / 44)$ of the cases. The CD34 positivity, together with typical muscle-markers positivity, as $\alpha$-SMA and desmin, in an extremely minority of tumours ( $\alpha$-SMA positivity in 6 cases on 40 tested, $15 \%$ and desmine positivity in 2/39 examined cases, $5.1 \%$ ), suggest a probable fibroblastic rather than myofibroblastic differentiation. When examined, the tumour cells also show an immunoreactivity for Vimentin. Another interesting finding is the expression of Estrogen receptor and/or Progesterone receptors by neoplastic cells $[5,14-16]$, which can suggests the role of an hormonal disturbance in the pathogenetic mechanisms of this tumour. When evaluated, all cases of CA show h-Caldesmon negativity (5/5 cases, $100 \%)$ and Keratin negativity (6/6 cases, $100 \%)$.

Multifocal or diffuse p16 expression is present in the atypical or sarcomatous areas of the CA, whilst is scattered or absent in usual CA [9]. In Table 4 are summarized the 
Table 2 Clinical features of 6 cases of extra-pelvic Cellular Angiofibroma

\begin{tabular}{llllllll}
\hline Case & Age & Author & Site & Size $($ media, cm) & Treatment & Follow-up (Months) & Recurrence \\
\hline 75 & 52 & Chen & Left hip & 3,5 & Local excision + reexcision & UK & UK \\
76 & 63 & Flucke & Knee lateral & 4 & Simple excision & 45 & NER \\
77 & 43 & Val-Bernal & Chest wall & 7 & Simple excision & 203 & NER \\
78 & 38 & Val-Bernal & Left hypocondrium & 3,5 & Simple excision & 104 & NER \\
79 & 60 & Mandato & Retroperitoneim pelvicc & 3,9 & Simple excision & 6 & NER \\
80 & 20 & Ahmadnia & Left axilla + both breast & $/$ & Simple excision & 12 & NER \\
\hline
\end{tabular}

NER not evidence of recurrence, UK unknown

immunohistochemical findings in the other soft tissue tumors compared with CA $[17,18]$.

\section{Discussion}

Cellular angiofibroma is a quite recently described rare, benign stromal tumour that occurs equally among men and women: in female patients, CA most frequently arises in the vulvo-vaginal region, although there are described a lot of pelvic and extra-pelvic cases. Women are affected most often in the fifth decade (mean age 46.1 years), earlier than men, affected in the seventh decade. CA is characterized by its small size (mean value $3.6 \mathrm{~cm}$ ) and usually well-circumscribed margins; it tends to be an asymptomatic and slowly enlarging mass, so CA tends to gradually increase in size after approximately 1-2 asymptomatic years, inducing women to check with their doctor long time after the tumour onset. CA is usually misdiagnosed with a Bartholin's cyst $(12 / 25,48 \%$ of cases), a not-specific solid mass $(7 / 25$, $28 \%$ of cases), vulval cyst $(3 / 25,12 \%$ of cases), leyomioma (2/12, $8 \%$ of cases) and lipoma (1/25, $4 \%$ of cases). Six extra-pelvic CA are reported in literature. Exceptionally, a young woman presented both vulvar and extra-pelvic CA, particularly two vulvar CA on the right and the left labia majora and three extravulvar $\mathrm{CA}$ on the left axilla and both breasts were reported [10].

Nevertheless exist exceptional early symptomatic forms, as well as our described case-report [11] in which the woman complained coxalgia due to tumour's position, in retroperitoneal site, very near to obturator nerve.

There are many mesenchymal tumour which enter into the differential diagnosis with CA as spindle cell lipoma, solitary fibrous tumour, mammary-type myofibroblastoma, angiomyfibroblastoma, aggressive angiomyxoma and smooth muscle tumour (Table 4). Exceptionally, CA has been diagnosed with these mesenchymal tumours, such as with lipoma [19].

Spindle cell lipoma was first described by Enzinger and Harvey [20] in 1975 as a benign lipomatous tumour with a predilection for shoulder, back and posterior neck region of middle-aged to elderly men. Occasional cases may occur in a wide variety of sites, including one reported case arising in the vulva [21]. The tumour consists of mature adipocytes, bland spindle cells and short bundles of brightly eosinophilic ropy collagen [7]. In fact, CA and spindle cell lipoma have similar histological features, but can be distinguished by the rarity of spindle cell lipoma in vulvovaginal region and the presence, in CA, of more numerous vessels with thickened, hyalinized walls, compared with capillary-sized thinwalled vessels in spindle cell lipoma. The immunostaining is not helpful because the spindle cells of both tumours are CD34 positive, in particular CD34 is positive in about $60 \%$ of CA and in $100 \%$ of spindle cell lipoma [8].

Solitary fibrous tumour has been reported in a wide variety of locations, including vulva and perineum [22, 23]. This tumour shows a patternless spindle cell proliferation of alternating hypercellular and hypocellular areas, associated with dense collagen bundles, stromal keloidal-type hyalinization and hemangiopericytoma-like vessels [8]. Both solitary fibrous tumour and CA may contain fat in the lesion [24] and show often positivity for CD34 [8], but CA differs due to more evenly distributed cellularity, bland spindle cells with short bundles of collagen and more rounded small- to medium-sized vessels.

Mammary-type myofibroblastoma, as we know for its typical breast localization, has been described also at extramammary locations, especially in the inguinal region, with a male predominance [25]. Grossly, this lesion appears as a well circumscribed, nodular mass and, microscopically, it is composed of spindle cells and adipose tissue, separated by coarse bundles of hyalinized collagen. In comparison of CA, the vessels in mammarytype myofibroblastoma are incospicuous and the spindle cells have a more fascicular arrangement. The tumour cells consistently exhibit coexpression of desmin and CD34 [25].

All these described tumours share similar morphologic features and are characterized by bland ovoid to spindleshaped cells with wispy collagen, variably sized thickwalled blood vessels and immunoreactivity to CD34.

In consideration of the clinical features, aggressive angiomyxoma ( $A A$ ) and angiomyofibroblastoma ( $A M F$ ) should also be included in the differential diagnosis of CA. The former is a typical locally recurring tumour of 
Table 3 Immunohistochemical features of cellular angiofibroma in women reported in literature

\begin{tabular}{|c|c|c|c|c|c|c|c|c|c|c|c|c|c|c|c|}
\hline Case & Author & Vimentin & CD34 & $S-100$ & a-SMA & Desmin & Keratin & EMA & ER & $P R$ & h-Caldesmon & CD10 & CD99 & CD31 & CD117 \\
\hline 1 & Nucci & + & - & - & - & - & - & - & & & & & & & \\
\hline 2 & Nucci & + & - & - & - & - & - & - & & & & & & & \\
\hline 3 & Nucci & + & - & - & - & - & - & - & & & & & & & \\
\hline 4 & Nucci & + & - & - & - & - & - & - & & & & & & & \\
\hline 5 & Nucci & & + & & & & & & & & & & & & \\
\hline 6 & Nucci & & + & & & & & & & & & & & & \\
\hline 10 & Dargent & + & + & - & + & - & & - & + & + & - & & + & - & - \\
\hline 11 & Dargent & + & & - & & & & - & + & + & - & & + & - & - \\
\hline 12 & Iwasa & & + & - & + & + & & & + & + & & & & & \\
\hline 13 & Iwasa & & + & - & + & + & & & + & + & & & & & \\
\hline 14 & Iwasa & & + & - & + & - & & & + & + & & & & & \\
\hline 15 & Iwasa & & + & - & + & - & & & + & + & & & & & \\
\hline 16 & Iwasa & & + & - & - & - & & & + & + & & & & & \\
\hline 17 & Iwasa & & + & - & - & - & & & - & + & & & & & \\
\hline 18 & Iwasa & & + & - & - & - & & & - & + & & & & & \\
\hline 19 & Iwasa & & + & - & - & - & & & - & + & & & & & \\
\hline 20 & Iwasa & & + & - & - & - & & & - & + & & & & & \\
\hline 21 & Iwasa & & + & - & - & - & & & - & - & & & & & \\
\hline 22 & Iwasa & & + & - & - & - & & & & & & & & & \\
\hline 23 & Iwasa & & - & - & - & - & & & & & & & & & \\
\hline 24 & Iwasa & & - & - & - & - & & & & & & & & & \\
\hline 25 & Iwasa & & - & - & - & - & & & & & & & & & \\
\hline 26 & Iwasa & & - & - & - & - & & & & & & & & & \\
\hline 27 & Iwasa & & - & - & - & - & & & & & & & & & \\
\hline 28 & Iwasa & & - & - & - & - & & & & & & & & & \\
\hline 29 & Iwasa & & - & - & - & - & & & & & & & & & \\
\hline 30 & Iwasa & & - & - & - & - & & & & & & & & & \\
\hline 31 & Iwasa & & - & - & - & - & & & & & & & & & \\
\hline 32 & Iwasa & & - & - & - & - & & & & & & & & & \\
\hline 33 & Iwasa & & - & - & - & - & & & & & & & & & \\
\hline 34 & Iwasa & & - & - & - & - & & & & & & & & & \\
\hline 35 & Iwasa & & - & - & - & - & & & & & & & & & \\
\hline 38 & McCluccage & + & - & - & - & - & & + & + & + & - & - & & & \\
\hline 39 & McCluccage & + & + & - & - & - & & - & - & & & & & & \\
\hline 40 & McCluccage & + & + & - & - & - & & - & + & + & - & + & & & \\
\hline 41 & McCluccage & + & - & - & - & - & & - & + & + & - & - & & & \\
\hline 69 & Rua Micheletti & + & - & - & - & - & & & & & & & & & \\
\hline 70 & Kerkuta & + & - & - & - & - & & & + & + & & & & & \\
\hline 71 & Lane & + & + & - & - & - & & & + & + & & & & & \\
\hline 74 & Arsenovic & + & + & - & - & - & & & + & + & & & & & \\
\hline 73 & Maggiani & & - & - & + & - & & & + & + & & & & & \\
\hline 76 & Val-Bernal & + & + & - & - & - & - & & - & + & & & + & & \\
\hline 77 & Val-Bernal & + & - & & - & & - & - & & & & & & & \\
\hline 78 & Mandato & & + & & & & & & + & & & & & & \\
\hline
\end{tabular}


Table 4 Immunohistochemical features of CA and vulvar tumours for differential diagnosis

\begin{tabular}{|c|c|c|c|c|c|c|c|c|c|c|c|c|c|}
\hline & Vimentin & CD34 & S-100 & a-SMA & Desmin & Keratin & EMA & ER & $\mathrm{PR}$ & h-Caldesmon & CD-10 & ACTIN & STAT-6 \\
\hline Agressive Angiomyxoma & $3+$ & $1+$ & & $1+$ & $3+$ & & & $3+$ & $3+$ & & & $1+$ & \\
\hline Angiomyfibroblastoma & $3+$ & $1+$ & & $3+$ & $3+$ & & & $3+$ & $3+$ & & & $3-/ 1+$ & \\
\hline Ffibroepithelial stromal polyp & $3+$ & & & & $3+$ & & & $1+$ & $1+$ & & & $1+$ & \\
\hline Solitary fibrous tumour & & $3+$ & & & & & & & & & & & $3+$ \\
\hline Smooth muscle neoplasm & & & & & $3+$ & & & & & & & $3+$ & \\
\hline Spindle cell lipoma & & $3+$ & & & & & & & & & & & \\
\hline Angiofibroma of soft tissue & & $1+$ & & $1+$ & $1+$ & & $2+$ & & & & & & \\
\hline $\begin{array}{l}\text { Superficial myofibroblastoma of the } \\
\text { lower female genital tract }\end{array}$ & $3+$ & $1+$ & 3- & $1+$ & $2+$ & 3- & 3- & $3+$ & $3+$ & & & & \\
\hline Cellular Angiofibroma & $3+$ & $2+$ & $3-$ & $2-$ & $2-$ & & 3- & $3+$ & $3+$ & $2-$ & & $3-$ & \\
\hline
\end{tabular}

(3+): most of cases positive; (2+): half of cases positive; (1+): few/some cases postive; (3-): typically negative; (2-): usually negative

the vulvo-vaginal/perineal/inguinal regions, which occurs mainly in women in third to fifth decades [26-28]. It is easily distinguishable from CA because it is generally a large deep-seated lesion, poorly circumscribed with infiltrative edges: AA tends to display an infiltrative growth with entrapment of mucosal glands, fat, muscle and nerves. Microscopically, aggressive angiomyxoma is hypocellular, compared with CA, and it is composed of short spindle tumour cells with minimal atypia in myxoid stroma. Small clusters of smooth muscle cells surrounding or "spinning off from" blood vessels are a characteristic feature of AA [3]. There is a variable positivity for desmin, smooth muscle actin and CD34 [7, 27, 28].

Angiomyofibroblastoma is a benign tumour most commonly occurring in the vulva of peri- and post-menopausal women $[29,30]$. Like CA, AMF is well circumscribed, even well demarcated, usually with a thin fibrous capsule but, unlike to CA, it is characterized by alternating hypocellular and hypercellular areas, together with multinucleate cells and epithelioid or plasmacytoid cells arranged in cords and nets around vessels. In fact, the characteristic feature of angiomyofibroblastoma is the perivascular accentuation of tumor cells $[29,30]$. In aid to differential diagnosis, the immunochemistry is very useful because the tumour cells of AMF express desmin and rarely CD34 and smooth muscle actin $[7,29,30]$.

Finally, vulvar smooth muscle tumours can be easily distinguished from CA because the latter lacks typical features of smooth muscle differentiation and it is usually desmin negative. The smooth muscle neoplasm are classically composed of cells with blunt-ended nuclei and eosinophilic cytoplasm, although these histological features could be absent when the tumour is localized in the vulvovaginal region.

The immunohistochemical features of CA may be helpful in differential diagnosis with the other vulvovaginal soft tissue tumours. An interesting immunohistochemical finding is the Estrogen and/or Progesterone receptors
(ER/PR) expression by the CA. The occurrence of CA during menopausal transition and post-menopausal period and the description of a two cases associated with longterm estrogen replacement therapy $[11,15]$ support the hypothesis of an hormonal pathogenetic origin. However, the direct role of these steroids in the CA pathogenesis still remains unclear, since a subset of mesenchymal cells of the distal female genital tract normally expresses these receptors and, at the same time, the neoplastic cells in other soft tissue disorders, arising from the vulva, may also show immunoreactivity for ER and/or PR [31].

Immunohistochemistry may be also helpful in differential diagnosis between usual CA and CA with atypia or sarcomatous transformation. p16 expression is commonly negative in usual CA whilst is multifocal or diffuse in CA with atypia or sarcomatous transformation [9]. The p16 and p53 represent tumour suppressor genes involving in the regulation of molecular pathways that may play a role in the tumour progression in sarcomas: overexpression of p16 may participate in the molecular mechanisms underlying the atypical or sarcomatous transformation seen in some subset of CA [9].

Recently fluorescent in situ hybridization (FISH) [13] has shown a genetic relationship between $\mathrm{CA}$, mammarytype myofibroblastoma and spindle cell lipoma. The same monoallelic or biallelic loss of retinoblastoma (RB) 1 (13q14), suggested a spectrum of one entity with morphological variations dependent on anatomic location. This argument doesn't apply to solitary fibrous tumour as pubblished by Fritchie et al. [26] that shows the absence of monoallelic/biallelic RB1 loss by FISH, arguing against the concept the solitary fibrous tumour is genetically related to the other three entities.

$\mathrm{RB}$ is an important tumor suppressor protein that plays a crucial role in cell cycle progression [32]. RB gene is located at 13q14. Disruptions to the RB protein and to the pathway controlled by RB confer proliferative advantage to tumor cells [33]. In 13q14 gene is located 
also a tumor suppressor called Forkhead box protein O1 (FOXO1) [34]. FOXO1 is a transcription factor associated with apoptosis, cell cycle regulation, DNA repair and resistance to oxidative stress [34]. A loss of FOXO1 expression was recently associated with CA [35]. FOXO1 transcription factor induces an increased expression of manganese superoxide dismutase (MnSOD) resulting in an elimination of the reactive oxygen species (ROS) [36]. Hence, loss of FOXO1 expression is associated with a decreased expression of MnSOD and, as consequence, an increased intracellular ROS generation causing mutations in proto-oncogenes and tumor suppressor genes [37]. In fact, increased intracellular ROS induces p38 mitogenactivated protein (MAPK) pathway and may be linked to the tumorigenesis [36-38].

ROS can cause tumor development through cellular proliferation, tumor cell invasion, angiogenesis and cancer stem cell survival [37]. Also mammary and vaginal myofibroblastomas can present a monoallelic deletion of FOXO1 [31]. Hence, RB1 and FOXO1 loss of expression could be implicated in the pathogenesis of CA [13, 39]. RB1 and FOXO1 FISH analysis could be used to support CA diagnosis but the specificity is uncertain [13].

Also CA pathogenesis is still unclear, both sexual hormones and ROS has been proposed. Although human papillomavirus (HPV) E7 oncoprotein bind RB protein causing a loss of function [40], to our knowledge no role of infections in the pathogenesis of CA has been studied.

$\mathrm{CA}$ appears to behave in a benign fashion, since there is no report of tumours that progressed with metastasis and there is described only a recurrent case [12]. The primary and the recurrent CA consisted of a well circumscribed solid white mass of 4 and $6.5 \mathrm{~cm}$ respectively. The histology of both lesions didn't consistently differ: the recurrent lesion showed foci of increased cellularity and decreased vascularity compared with the original specimen although there were no histological features to suggest malignancy and 33 months after the excision of the recurrent $\mathrm{CA}$, there were no evidences of further local recurrence.

In the majority of the analysed cases, the surgical approach consists of a simple local excision or a "shelling out" and these treatments seem to be adequate also in case of atypia and/or sarcomatous transformation where the literature suggests a radical excision with free margins $[9,12]$. To date, we are not aware of any cases of metastases of these tumours with atypia/sarcomatous features, suggesting that morphological atypical or sarcomatous aspects don't necessarily confer an aggressive biologic behaviour to CA. Moreover, only 5 cases (5/18, $27.8 \%$ ) of re-excision because involved surgical margins has been reported but this method doesn't represent an elective procedure because the tumour is usually treated with a local excision also when there are positive surgical margins, as showed in the remaining 13 cases $(13 / 18$, $72.2 \%)$ with positive surgical margins, although no recurrences or metastasis have been reported. Therefore, considering that also cases of CA with positive margins don't recur, no wide excision should be required. Given the relative sensitivity of the most frequently affected anatomic sites, there seems to be no justification for attempting to obtain a larger surgical margins [3].

\section{Conclusions}

In summary, CA in women represents a distinct benign neoplasm with a broad anatomic distribution even if it is mainly localized in the vulvo-vaginal area. This lesion may exhibit some variations in its phenotypic features, as well as atypia and morphologic features of sarcomatous transformation but these characteristics seem not to predispose to a malignant fashion and recurrences. For these reasons, a treatment of simple local excision or a "shelling out" of the lesion appear to be adequate and effective to avoid recurrences and injuries to surrounding tissues.

\section{Abbreviations}

CA: Cellular angiofibroma; AA: Aggressive angiomyxoma; AMF: Angiomyofibroblastoma; ER: Estrogen receptor; PR: Progesterone receptor; FISH: Fluorescent in situ hybridization; RB: Retinoblastoma; FOXO1: Forkhead box protein O1; MnSOD: Manganese superoxide dismutase; ROS: Reactive oxygen species; MAPK: Mitogen-activated protein; HPV: Human papillomavirus.

\section{Competing interests}

The authors declare that they have no competing interests.

\section{Author's contributions}

VDM and SS substantially contributed to design the study, to collect data and to analyze the results. AC partecipated in revising pathological and immunohistochemical data and provided for the images. LA helped to conceived of the manuscript. MA and GBLS revised critically the work and they gave final approval of the version to be published. All authors read and approved the final manuscript.

\section{Acknowledgements}

The authors thank the pathologists and clinicians who kindly contributed to clinical and follow-up data: Dr Nebojosa N. Arsenovic, UK; Dr Jean Louis Dargent, Belgium; Dr Adilha Rua Micheletti, Brasil; Dr Jose Fernando Val Bernal, Spain.

\section{Author details}

${ }^{1}$ Unit of Obstetrics and Gynecology, IRCCS-Arcispedale S. Maria Nuova di Reggio Emilia, Viale Risorgimento n 80, Reggio Emilia, Italy. ${ }^{2}$ Unit of Pathology, IRCCS-Arcispedale S. Maria Nuova di Reggio Emilia, Reggio Emilia, Italy. ${ }^{3}$ Unit of Obstetrics and Gynecology, University of Modena e Reggio Emilia, Reggio Emilia, Italy.

Received: 20 March 2015 Accepted: 9 July 2015

Published online: 19 July 2015

\section{References}

1. Nucci MR, Granter SR, Fletcher CDM. Cellular angiofibroma: a benign neoplasm distinct from angiomyofibroblastoma and spindle cell lipoma. Am J Surg Pathol. 1997;21:636-44.

2. Laskin WB, Fetsch JF, Mostofi FK. Angiomyofibroblastoma-like tumor of the male genital tract. Analysis of 11 cases with comparison to female angiomyofibroblastoma and spindle cell lipoma. Am J Surg Pathol. 1998;22:6-16. 
3. Iwasa Y, Fletcher CDM, Iwasa Y, Fletcher CD. Cellular angiofibroma: clinicopathologic and immunohistochemical analysis of 51 cases. Am J Surg Pathol. 2004;28:1426-35.

4. Garijo MF, Val-Bernal JF. Extravulvar subcutaneous cellular angiofibroma. J Cutan Pathol. 1988;25:327-32.

5. Val-Bernal JF, Rubio S, Garijo F, Gonzalex-Vela MC. Extragenital subcutaneous cellular angiofibroma-case report. APMIS. 2007;115:254-8.

6. Norris HJ, Taylor HB. Polyps of the vagina. A benign lesion resembling sarcoma botryoides. Cancer. 1966;19:227-32.

7. Nucci MR, Fletcher CDM. Vulvovaginal soft tissue tumours: update and review. Histopathology. 2000;36:97-108.

8. Fletcher CDM, Unni KK, Mertens F. World Health Organization Classification of tumours: pathology and genetics of tumours of soft tissue and bone. Lyon: IARC; 2002.

9. Chen E, Fletcher CDM. Cellular angiofibroma with Atypia or Sarcomatous transformation: clinicopathologic analysis of 13 cases. Am J Surg Pathol. 2010;34:707-14.

10. Ahmadnia H, Kamalati A, Dolati M, Akhavan Rezayat A, Katebi M. Angiofibroma of the vulva. J Cutan Med Surg. 2014;18:203-5.

11. Mandato VD, Aguzzoli L, Cavazza A, Abrate M, Silvotti M, La Sala GB. Coxalgia? Call the gynecologist. J Minim Invasive Gynecol. 2015;22:663-7.

12. McCluggage WG, Perenyei M, Irwin ST. Recurrent cellular angiofibroma of the vulva. J Clin Pathol. 2002:55:477-9.

13. Flucke U, Van Krieken JM, Mentzel T. Cellular angiofibroma: analysis of 25 cases emphasizing its relationship to spindle cell lipoma and mammary myofibroblastoma. Mod Pathol. 2011;24:82-9.

14. McCluggage WG, Ganesan R, Hirschowitz L, Rollason TP. Cellular angiofibroma and related fibromatous lesions of the vulva: report of a series of cases with a morphological spectrum wider than previously described. Histopathology. 2004;45:360-8.

15. Lane JE, Walker AN, Mullis EN, Etheridge JG. Case report: cellular angiofibroma of the vulva. Ginecolo Oncol. 2001;81:326-9.

16. Kerkuta R, Kennedy CM, Benda JA, Galask RP. Vulvar cellular angiofibroma: a case report. Am J Obstet Gynecol. 2005;193:1750-2.

17. McCluggage WG. Recent developments in vulvovaginal pathology. Histopathology. 2009:54:156-73.

18. Sugita S, Aoyama T, Kondo K, Keira Y, Ogino J, Nakanishi K, et al. Diagnostic utility of NCOA2 fluorescence in situ hybridization and Stat6 immunohistochemistry staining for soft tissue angiofibroma and morphologically similar fibrovascular tumors. Hum Pathol. 2014:45:1588-96.

19. Arsenovic NN, Abdulla K, Terzic M, Reed M. Synchronous presence of cellular angiofibroma and lipoma in vulvoinguinal region: a unique case report. Am J Dermatopathol. 2009;31:468-71.

20. Enzinger FM, Harvey DA. Spindle cell lipoma. Cancer. 1975:36:1852-9.

21. Reis-Filho JS, Milanezi F, Soares MF, Fillus-Neto J, Schmitt FC. Intradermal spindle cell/pleomorphic lipoma of the vulva: case report and review of the literature. J Cutan Pathol. 2002;29:59-62.

22. Fukunaga M. Atypical solitary fibrous tumor of the vulva. Int J Gynecol Pathol. 2000;19:164-8.

23. Suster $\mathrm{S}$, Nascimento AG, Miettinen M, Sickel JZ, Moran CA. Solitary fibrous tumors of soft tissue. A clinicopathologic and immunohistochemical study of 12 cases. Am J Surg Pathol. 1995;19:1257-66.

24. Guillou L, Gebhard S, Coindre J-M. Lipomatous hemangiopericytoma: a fat-containing variant of solitary fibrous tumor? Clinicopathologic, immunohistochemical, and ultrastructural analysis of a series in favor of a unifying concept. Hum Pathol. 2000;31:1108-15.

25. McMenamin ME, Fletcher CDM. Mammary-type myofibroblastoma of soft tissue. A tumor closely related to spindle cell lipoma. Am J Surg Pathol. 2001:25:1022-9.

26. Fritchie KJ, Carver P, Sun Y, Batiouchko G, Billing SD, Rubin BP, et al. Solitary Fibrous Tumor: Is there a molecular relationship with cellular angiofibroma, spindle cell lipoma and mammary-type myofibroblastoma? Am J Clin Pathol. 2012;137:963-70.

27. Fetsch JF, Laskin WB, Lefkowitz M, Kindblom LG, Meis-Kindblom JM Aggressive angiomyxoma. A clinicopathologic study of 29 female patients. Cancer. 1996:78:79-90

28. Granter SR, Nucci MR, Fletcher CDM. Aggressive angiomyxoma: reappraisal of its relationship to angiomyofibroblastoma in a series of 16 cases. Histopathology. 1997;30:3-10
29. Fletcher CD, Tsang WY, Fisher C, Lee KC, Chan JK. Angiomyofibroblastoma of the vulva. A benign neoplasm distinct from aggressive angiomyxoma. Am J Surg Pathol. 1992;16:373-82.

30. Laskin WB, Fetsch JF, Tavassoli FA. Angiomyofibroblastoma of the female genital tract: analysis of 17 cases including a lipomatous variant. Hum Pathol. 1997:28:1046-55.

31. Dargent JL, De Saint AN, Galdon MG, Valaeys V, Cornut P, Noel JC. Cellular angiofibroma of the vulva: a clinicopathological study of two cases with documentation of some unusual features and review of the literature. J Cutan Pathol. 2003;30:405-11.

32. Weinberg RA. The retinoblastoma protein and cell cycle control. Cell. 1995;81:323-30.

33. Knudsen ES, Knudsen KE. Tailoring to RB: tumour suppressor status and therapeutic response. Nat Rev Cancer. 2008;8:714-24

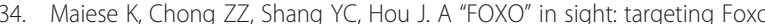
proteins from conception to cancer. Med Res Rev. 2009;29:395-418.

35. Arakaki K, Chinen K, Kamiya M, Tanabe Y, Tawata N, Ikehara F, et al. Evidence for an association between increased oxidative stress and derangement of $\mathrm{FOXO1}$ signaling in tumorigenesis of a cellular angiofibroma with monoallelic 13q14: a case report. Int J Clin Exp Pathol. 2014;7:8972-9.

36. Greer EL, Brunet A. FOXO transcription factors at the interface between longevity and tumor suppression. Oncogene. 2005;24:7410-25.

37. Reuter S, Gupta SC, Chaturvedi MM, Aggarwal BB. Oxidative stress, inflammation, and cancer: how are they linked? Free Radic Biol Med. 2010:49:1603-16

38. Zarubin T, Han J. Activation and signaling of the p38 MAP kinase pathway Cell Res. 2005:15:11-8

39. Maggiani F, Debiec-Rychter M, Vanbockrijck M, Sciot R. Cellular angiofibroma: another mesenchymal tumour with 13 q14 involvement, suggesting a link with spindle cell lipoma and (extra)-mammary myofibroblastoma. Histopathology. 2007;51:410-2.

40. Yim EK, Park JS. The role of HPV E6 and E7 oncoproteins in HPV-associated cervical carcinogenesis. Cancer Res Treat. 2005;37:319-24.

\section{Submit your next manuscript to BioMed Central and take full advantage of:}

- Convenient online submission

- Thorough peer review

- No space constraints or color figure charges

- Immediate publication on acceptance

- Inclusion in PubMed, CAS, Scopus and Google Scholar

- Research which is freely available for redistribution 